\title{
Reabilitação psicossocial e inclusão social de pessoas com problemas decorrentes do uso de álcool e outras drogas: impasses e desafios*
}

Psychosocial rehabilitation and social inclusion of people with issues resulting from alcohol and drug use: deadlocks and challenges (abstract: p. 14)

Rehabilitación psicosocial e inclusión social de personas con problemas provenientes del uso de alcohol y de otras drogas: callejones sin salida y desafíos (resumen: p. 14)

Laís Ramos Sanches ${ }^{(a)}$

<laisramossanches@gmail.com>

Marcelo Dalla Vecchia ${ }^{(\mathrm{b})}$

<mdvecchia@ufsj.edu.br>

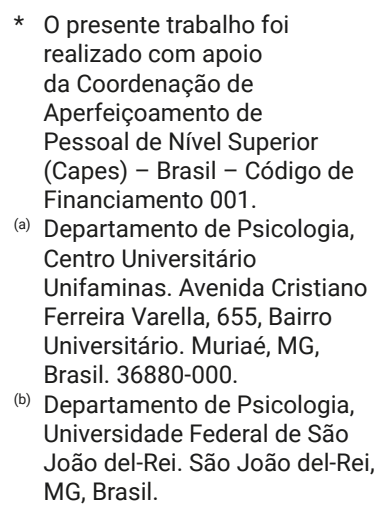

(b) Departamento de Psicologia, Universidade Federal de São João del-Rei. São João del-Rei, MG, Brasil.

A reabilitação psicossocial e inclusão social, cujas definições estão relacionadas à possibilidade de circulação no território e participação em sociedade, constituem-se em desafios dos profissionais de serviços substitutivos aos hospitais psiquiátricos. Investigam-se as dificuldades que os profissionais encontram no desenvolvimento e implantação das estratégias de reabilitação e inclusão em tais serviços. Foram realizadas entrevistas semiestruturadas com profissionais de um Centro de Atenção Psicossocial - Álcool e Outras Drogas (Caps-AD), exploradas via análise de conteúdo do tipo temática. Os principais impasses relatados foram os estigmas sociais atribuídos aos usuários de drogas, a escassez de atividades de trabalho e geração de renda, o distanciamento da família durante o tratamento e o financiamento insuficiente para ações estratégicas. Trata-se de fenômenos complexos e que precisam de atenção do poder público, por criarem barreiras às estratégias de reabilitação e inclusão social.

Palavras-chave: Reabilitação psicossocial. Inclusão social. Drogas. Políticas públicas.

Sanches LR, Vecchia MD. Reabilitação psicossocial e inclusão social de pessoas com problemas decorrentes do uso de álcool e outras drogas: impasses e desafios. Interface (Botucatu). 2020; 24: e200239 https://doi.org/10.1590/interface.200239 


\section{Introdução}

O consumo de substâncias psicoativas não é recente na humanidade e apresenta funções diversas conforme o contexto histórico e sociocultural ${ }^{1}$. A partir dos anos 1980, emergem dispositivos de atenção ao uso prejudicial de álcool e outras drogas, os Caps-AD que, a partir da lógica comunitária, visa acolher os usuários considerando a sua singularidade e cidadania ${ }^{2}$. O Caps-AD é um dispositivo da Rede de Atenção Psicossocial (Raps), instituída pela Portaria n. 3.088, em 2011. A Raps tem como objetivo a oferta de cuidado aos usuários de álcool e outras drogas pautado nos direitos humanos, autonomia, liberdade e acesso aos serviços com vistas ao cuidado integral ${ }^{3}$.

De acordo com a Política do Ministério da Saúde para a Atenção Integral a Usuários de Álcool e Outras Drogas (PAIUAD), o Caps-AD tem por objetivo o atendimento pautado na redução de danos $(\mathrm{RD})^{4}$, desenvolvendo atividades terapêuticas, cuidado à família e promoção da reabilitação psicossocial e reinserção social dos usuários, eixos fundamentais para a atenção integral. Em abril de 2019, foi aprovada a nova Política Nacional Sobre Drogas por meio do Decreto n. 9.7615, que exclui a RD como diretriz das ações de cuidado.

A reabilitação psicossocial é compreendida como um processo de reconstrução, exercício da cidadania e contratualidade nos âmbitos familiar, social e do trabalho ${ }^{6}$. Trata-se, também, da capacidade de o sujeito realizar trocas sociais, isto é, aumentar o seu poder de estabelecer contratos sociais em seu cotidiano?

$\mathrm{Na} \mathrm{PAIUAD}^{4}$, a reinserção social, por sua vez, é mencionada como um processo individual e coletivo, abrangendo uma dimensão individual na medida em que visa proporcionar à pessoa a construção de um equilíbrio nas diversas esferas de sua vida, e se aproxima do âmbito coletivo a partir da ampliação das possibilidades de atenção, cuidado e construção de novos projetos de vida ${ }^{8}$.

A utilização dos termos "reabilitação psicossocial” e "reinserção social” pode ser observada em documentos normativos como leis e portarias, ${ }^{4,8-11}$, assim como em trabalhos acadêmicos, abarcando procedimentos e finalidades similares, mas que, em tese, referem-se a processos distintos.

Sanches e Vecchia ${ }^{12}$, em revisão acerca dos conceitos de reabilitação psicossocial e reinserção social, verificaram que a reabilitação psicossocial é abordada na literatura com um foco individual e está pautada teoricamente em uma concepção funcionalista e na noção de contratualidade. Observaram a inexistência de um embasamento teórico consistente que apresente a reinserção social no campo de álcool e outras drogas, propondo a inclusão social como um constructo relevante e que remete ao processo de participação e convivência comunitária. Assim, o presente trabalho opta pela utilização dos termos "reabilitação psicossocial" e "inclusão social”, sendo que a inclusão social assume um debate pautado na dialética da exclusão/inclusão, compreendendo que a sociedade exclui para incluir de forma indigna determinados grupos sociais, como os usuários de drogas, que se localizam à margem da sociedade no que se refere ao acesso às políticas sociais e aos espaços de lazer, cultura, saúde, renda, entre outros ${ }^{12,13}$.

O presente estudo buscou discutir os principais impasses e desafios que envolvem as práticas dos profissionais de um Caps-AD no processo de desenvolvimento das açôes de reabilitação psicossocial e inclusão social de pessoas com problemas decorrentes 
do uso de drogas. Espera-se que pesquisas acerca dessa temática possam auxiliar na reformulação de políticas atentas às especificidades de cada processo, evitando a disseminação de práticas superpostas e/ou fragmentadas.

\section{Metodologia}

A pesquisa foi realizada em um Caps-AD que funciona há nove anos e está localizado em uma cidade no interior de Minas Gerais. Foram realizadas 14 entrevistas semiestruturadas com profissionais do Caps- $\mathrm{AD}$ cuja equipe contempla psicólogos, terapeutas ocupacionais, técnicos em enfermagem, assistente social, monitoras de oficinas terapêuticas, médico psiquiatra, médico clínico geral, recepcionista e motorista. Foram incluídos na pesquisa os profissionais que atuam e oferecem algum serviço ou possuem contato com os usuários que frequentam o dispositivo, sendo que apenas uma profissional, auxiliar de serviços gerais, não se disponibilizou a participar. Os nomes dos participantes foram substituídos por pseudônimos de modo a garantir o anonimato. As entrevistas individuais foram previamente agendadas com os profissionais do serviço via telefone e foram realizadas na sede do Caps-AD da cidade em questão.

Foram utilizadas entrevistas semiestruturadas, permitindo ao entrevistador indagar acerca do tema proposto com base em tópicos, sem se limitar literalmente às perguntas formuladas ${ }^{14}$. Duarte ${ }^{15}$ postula que "entrevistas são fundamentais quando se precisa/deseja mapear práticas, crenças, valores e sistemas classificatórios de universos sociais específicos” (p. 215). Os tópicos abordados estavam relacionados à atuação profissional e atividades realizadas, à classificação dessas atividades como atividades de reabilitação psicossocial, reinserção social ou inclusão social, e as possibilidades e desafios na sua realização.

As entrevistas individuais foram submetidas à análise de conteúdo, que, de acordo com Bardin ${ }^{16}$, "aparece como um conjunto de técnicas de análise das comunicaçôes, que utiliza procedimentos sistemáticos e objetivos de descrição do conteúdo das mensagens” (p. 38). Assim, o conteúdo das mensagens é explicitado e sistematizado com a finalidade de fazer deduções lógicas e justificadas, levando em consideração o contexto, o emissor e as consequências dessas mensagens ${ }^{16}$.

Entre as modalidades de análise de conteúdo, foi utilizada a análise temática, que considera o tema uma unidade de significação que emerge do texto, possibilitando, então, recortá-lo em ideias e enunciados com significados isoláveis ${ }^{16}$. Nesse sentido, para Bardin ${ }^{16}$, a análise de conteúdo temática "consiste em descobrir os núcleos de sentido que compóem a comunicação e cuja presença ou frequência de aparição podem significar alguma coisa para o objetivo analítico escolhido” (p. 105). A análise de conteúdo temática foi realizada em três fases: pré-análise, exploração do material, e tratamento das informaçốes ${ }^{16}$. $\mathrm{Na}$ fase da pré-análise, foi realizada a transcrição das entrevistas e a leitura flutuante do material a ser analisado. Na segunda etapa, buscou-se identificar as categorias de análise, isto é, os temas que se repetiram no discurso dos participantes e que contribuíram para o alcance dos objetivos da pesquisa. Por fim, no tratamento das informaçôes, foi realizada a discussão das categorias, tendo em vista a apresentação dos resultados a partir de inferências, interpretaçôes e relaçóes com outras investigaçóes. 
A pesquisa foi autorizada pelo Caps-AD em questão e aprovada pelo Comitê de Ética em Pesquisa Envolvendo Seres Humanos da Universidade Federal de São João del-Rei (CAAE 68273517.1.0000.5545). As entrevistas foram agendadas e realizadas com os profissionais que concordaram em participar após a apresentação da pesquisa. $\mathrm{Na}$ apresentação, os potenciais participantes foram informados sobre sigilo, anonimato, anuência para utilização de um gravador digital e possibilidade de recusa em participar da pesquisa. Os entrevistados assinaram um Termo de Consentimento Livre e Esclarecido (TCLE), ficando com uma via, e concederam a entrevista.

Quanto aos nomes dos entrevistados, foram criados codinomes para resguardar os nomes verdadeiros dos participantes.

\section{Resultados e discussão}

\section{Estigma}

Uma das dificuldades para o processo de reabilitação psicossocial e inclusão social destacadas pelos entrevistados consiste no estigma social atribuído ao usuário de drogas. Isso corrobora os achados de Paiva et al. ${ }^{17}$ que indicam ser o estigma um amplificador dos desafios no processo de inclusão social do usuário. Silveira et al. ${ }^{18}$ apontam que o estigma constitui uma barreira no processo de busca e adesão ao tratamento de pessoas com problemas decorrentes do uso de drogas, influenciando, também, a forma como eles serão integrados à comunidade. Esse processo de estigmatização é mencionado por Carla:

Eles reclamam muito lá de fora, eles falam que a sociedade não aceita, eles já têm esse... estereótipo: “ah, eles não vão me aceitar, que eu sou alcoólatra”. (Carla)

Para Paiva et al. ${ }^{17}$, ainda há uma conotação moral atribuída ao consumo de substâncias psicoativas, que provoca a estigmatização desses sujeitos tanto pelos profissionais da saúde quanto pela sociedade em geral. A definição clássica de "estigma”, formulada por Goffman ${ }^{19}$, considera que este se refere a um atributo negativo e depreciativo de alguém, que o torna diferente dos outros. Parker ${ }^{20}$ postula a necessidade de se ampliar o debate acerca do estigma e encará-lo como um processo social ligado às relaçôes de poder e dominação. Silveira et al.${ }^{18}$, nessa direção, mencionam que o estigmatizador encontra-se em uma posição privilegiada quanto ao poder social, viabilizando que suas opinióes influenciem os demais.

Uma das consequências do processo de estigmatização é a desvalorização de si mesmo pelo sujeito estigmatizado, o que pode ser denominado "estigma internalizado"18.

Corrigan $^{21}$ indica que esses indivíduos se convencem dos estigmais sociais a eles atribuídos e desvalorizam a si próprios. Essa ideia pode ser observada no relato de Clara:

Porque muitos têm medo ou um preconceito neles mesmo estabelecidos, que o discurso deles mostra isso assim, de que "ah, eu sou doente, que eu não sei fazer nada, que eu não consigo fazer nada”. (Clara) 
Luíza associa o processo de estigmatização à discussão acerca da ilegalidade de algumas substâncias psicoativas:

[...] por causa também [...] da ilegalidade das drogas, né? Porque a gente vê que, por exemplo, o álcool, que é a que causa mais, tipo assim, violência, agressividade, causa mais dependência... às vezes não é tão [ênfase] assim, por ser legal não é tão ainda visto como aquele demônio, do que, por exemplo, crack, sabe? (Luíza)

Nesse sentido, é necessário discutir a política proibicionista e a "guerra às drogas", globalmente veiculada desde ao menos o início do século XX, período em que se reafirmava a ideia de "combate" às drogas como a um inimigo ${ }^{22}$. Tal premissa amplia o poder punitivo àqueles que consomem, produzem e comercializam substâncias psicoativas $^{23}$. Esse caráter criminalizador parte de uma distinção arbitrária entre as substâncias psicoativas tornadas ilícitas (como a maconha, a cocaína e a heroína) e as substâncias lícitas (como o álcool, o tabaco e a cafeína). Como consequência disso, produtores, comerciantes e consumidores de drogas ilícitas são tidos como criminosos e como inimigos de uma ordem social, enquanto os produtores, comerciantes e consumidores de drogas como a cerveja e tabaco agem na legalidade ${ }^{22,23}$.

Sobre isso, Felipe diz:

Acho que a dificuldade que o sujeito tem lá fora é que ele é muito reduzido à situação de uso. Então, as pessoas só enxergam... "ah, o fulano é a bebida, o beltrano é o crack" [...] Mas acho que isso dificulta, né? Como se fosse criando um lugar para esse sujeito, né? (Felipe)

Essa "marca social", que desvaloriza o sujeito perante a sociedade e a própria família, constitui-se em uma importante barreira para a reabilitação psicossocial e a inclusão social, uma vez que pode provocar a redução da circulação dos sujeitos em diversos espaços sociais que não são considerados o seu lugar, como expresso na fala de Felipe. Contraditoriamente, lugares destinados ao usuário de drogas por parte da sociedade que o estigmatiza não incluem festivais de música, biblioteca municipal e museus, locais mencionados pelos profissionais entrevistados, visto serem espaços que os usuários só costumam frequentar quando estão acompanhados pela equipe do serviço.

Dessa forma, infere-se que o estigma social e o estigma internalizado se constituem em obstáculos no processo de circulação nos espaços sociais, uma vez que há uma conotação moral atribuída ao fato de o sujeito fazer uso de drogas, principalmente quando se trata de drogas tornadas ilícitas.

\section{Escassez de atividades de trabalho e geração de renda}

A geração de trabalho e renda por meio de oficinas específicas aparece nas falas dos entrevistados como uma atividade ainda incipiente no serviço. Alguns profissionais relataram um esforço na busca de parcerias institucionais e convênios com cursos profissionalizantes, porém, tais iniciativas são mencionadas como a principal carência das açốes de reabilitação psicossocial e inclusão social. 
Júlia comenta essa dificuldade no âmbito do trabalho:

Uma questão que a gente não tá conseguindo é essa inserção no trabalho, por exemplo. E num vínculo assim, acadêmico, pra eles desenvolver e se capacitarem profissionalmente. (Júlia)

Ela ainda complementa que o trabalho pode contribuir para o resgate da autoestima e autoconfiança do usuário, mas que ainda há dificuldades na implementação dessas estratégias.

A utilização do trabalho no campo psiquiátrico passou por transformações ao longo do tempo. No século XVII, a atividade de trabalho era um recurso para manter uma ordem social imposta pelos órgãos de controle da burguesia, como a polícia e o Estado propriamente dito. Posteriormente, com uma nova ordenação prática e teórica no campo, advinda com Pinel, o trabalho foi usado como recurso terapêutico-moral, visando à cura da doença mental ${ }^{24}$. O trabalho dentro do manicômio, de acordo com Saraceno ${ }^{25}$, tinha como função a norma moral, o entretenimento e, inclusive, a exploração. $\mathrm{O}$ trabalho, nesse contexto, seria um indicador do funcionamento social do indivíduo e uma forma de adaptação social ${ }^{25}$. Já no fim do século XX, no movimento da reforma psiquiátrica, o trabalho tornou-se índice de reabilitação e inclusão social ${ }^{26}$. Por meio dele, busca-se a restituição da contratualidade e a posse de recursos para trocas sociais e exercício da cidadania ${ }^{25}$.

O entrevistado Pedro coloca como necessidade do serviço um avanço na realização de convênios com instituiçôes que possam oferecer capacitaçôes e vagas de emprego para os usuários do Caps-AD:

Eu acho que essa reinserção no trabalho passa pela questão de eles aprenderem um ofício e de terem onde trabalhar também. Porque não adianta nada eles terem um ofício se não tiverem oportunidade, né... E a outra vertente é aqueles que estiverem nesse período de transição para um trabalho fixo ou aqueles que não têm... Não vão ter condições mesmo de trabalhar num lugar fixo... seria... as oficinas geradoras de renda dentro da Associação, né? (Pedro)

Pedro, assim, propóe dois tipos diferentes de inserção por via do trabalho: as oficinas de geração de renda e o trabalho, propriamente dito, fora do Caps-AD. A associação mencionada pelo entrevistado é uma iniciativa que reúne usuários de três serviços: o Caps-AD, o Caps I e o Centro de Atenção Psicossocial Infantil (Capsi), sendo o Caps I voltado para pessoas em sofrimento mental mais severo e/ou persistente e o Capsi voltado para o atendimento de crianças e adolescentes com transtornos mentais graves e persistentes e que fazem uso de crack, álcool e outras drogas. O Capsi e Caps I são modalidades de Centros de Atenção Psicossocial que, assim como o Caps$\mathrm{AD}$, compóem a Raps ${ }^{10}$. O Caps I pode ser implementado em municípios com mais de vinte mil habitantes e o Capsi em municípios com mais de 150 mil habitantes ${ }^{10}$. 
(e)

A Associação de Usuários, nessa cidade, é um espaço a partir do qual os usuários se organizam, ampliam sua participação política e se fortalecem enquanto cidadãos. Entre as açôes que ocorrem por meio da Associação, mencionadas pela entrevistada Júlia, estão

[...] as feiras de bazar, de artesanato [...] eles fazem artesanato, tanto na oficina da [Associação] onde a gente tem oficinas de blocos [...] mas é interessante também a venda nas feiras, em que eles ficam também responsáveis pelas vendas. (Júlia)

Ainda que haja mençóes às dificuldades relacionadas à inclusão no mundo do trabalho, existe uma iniciativa na rede que busca contemplá-la. Pode-se inferir, no entanto, que essa iniciativa não é considerada suficiente para suprir a demanda dos usuários no que se refere à oportunidade de trabalho e de se sustentar por meio daquilo que é produzido e comercializado por meio da associação.

Essa dificuldade não é específica do Caps-AD e do município pesquisado: o acesso dos usuários à vida produtiva ainda é uma barreira a ser transposta no campo da saúde mental ${ }^{26}$. O trabalho se constitui em uma prática que legitima socialmente os indivíduos e possibilita a ampliação da qualidade de vida e dos níveis de saúde. Saraceno ${ }^{25}$ sustenta que o desenvolvimento de açóes voltadas para o trabalho se trata de um processo mais amplo do que realizar determinadas tarefas. Trata-se da possibilidade de promover a articulação do campo dos interesses, das necessidades e dos desejos, isto é, envolve o valor atribuído ao trabalho como um meio de sustento, mas também como meio de autorrealização ${ }^{25}$.

\section{Participação familiar no tratamento}

A participação da família no tratamento de pessoas com sofrimento mental no Brasil tem uma história recente, uma vez que até o fim da década de 1970 o tratamento tinha como característica central o asilamento, que afastava a família do cuidado ${ }^{27}$. Contemporaneamente, tem sido ressaltada a relevância da consolidação de uma rede comunitária para a inclusão social dos pacientes, fortalecendo os vínculos familiares e sociais, de modo a contribuir com os processos de reabilitação e inclusão social ${ }^{28}$. O enfoque ético-político da proposta de RD e a implantação de serviços substitutivos como os Caps-AD visa resgatar os controles sociais informais na prevenção e tratamento para o uso abusivo de substâncias, enfatizando o enfoque familiar no cuidado ${ }^{29}$. Esses controles sociais informais, denominados "controles societais", auxiliam na regulação que ocorre por meio da interlocução entre diversos agentes sociais e o usuário de substâncias psicoativas, seja na escola, em casa, no trabalho, por meio da mídia, nas ruas, etc ${ }^{30}$.

O uso de drogas deve levar em conta o contexto do usuário, que envolve os amigos, a rede social, os aspectos culturais e as relaçóes familiares ${ }^{31}$. Nesse sentido, o envolvimento da família no cuidado ao uso problemático de drogas torna-se fundamental, pois tende a fortalecer e a estender os benefícios para o sujeito em tratamento. Ocorre que a participação da família no tratamento é mencionada como uma dificuldade pelos entrevistados. Maria pontua que: 
[...] às vezes eu sinto uma dificuldade com adesão das famílias aos grupos, né? Porque eles não acham que eles têm que vir, quem tem que vir é a pessoa da casa que bebe. (Maria)

A fala de Maria sinaliza a existência de uma concepção entre as famílias de que a questão do uso de drogas daquele que está em tratamento no Caps-AD está apartada da família como um todo, tratando-se de um problema individual. A família pode atuar como fator tanto de proteção quanto de risco para o abuso de substâncias, sendo imprescindível compreender o contexto no qual estão inseridos o indivíduo, a família e as drogas para uma reflexão mais detida acerca dessa interação ${ }^{31}$. Em uma investigação de Sanches et al..$^{32}$, verificou-se que a família assume um importante papel tanto no processo de experimentação das drogas quanto no início do tratamento para a dependência, evidenciando tais fatores de risco e proteção. Nesse sentido, é necessário cautela ao atribuir um peso preponderante à família, uma vez que se trata de um processo multideterminado, com associação entre fatores psicossociais, culturais e farmacológicos ${ }^{29}$.

O afastamento da família e seu baixo envolvimento no tratamento é mencionado por todos os profissionais entrevistados. A família tem um lugar de destaque nas políticas públicas e na proteção social dos indivíduos, uma vez que ela e o Estado desempenham papéis de regulação e normatização nas ações cotidianas de cuidado ${ }^{33}$. Essa questão é destacada pelos entrevistados, todavia, a entrevistada Júlia indica em sua fala que tais famílias também precisam ser cuidadas:

A família, às vezes, já tá meio calejada, já confiou muito e foi frustrada. Muitas vezes, eles chegam aqui já nesse processo de tipo “Ah, chuta o balde, né?” [...] Já não tem mais tolerância, meio que desistem mesmo, né? (Júlia)

Além disso, a fala de Felipe revela o que é compreendido como um distanciamento do Estado com relação ao cuidado dessas famílias:

O Estado é muito ausente da vida dessas famílias e desses usuários... É transferido pra eles toda a responsabilidade. Na hora que o bicho pega mesmo, aciona a família que a família tem que se haver. (Felipe)

Rosa $^{34}$ sinaliza uma tensão na inclusão das famílias no tratamento, visto que alguns trabalhadores da saúde têm uma expectativa sobre sua participação que nem sempre corresponde às suas possibilidades reais. O cuidador, muitas vezes, sente-se estigmatizado e assume uma sobrecarga no cuidado que se soma aos cuidados domésticos. Essa sobrecarga, aliada às diversas tentativas frustradas de lidar com a questão, faz com que as famílias cheguem ao serviço sentindo-se impotentes, culpadas e desesperadas, apelando aos "especialistas" como capazes de oferecer uma solução final para seus problemas ${ }^{34}$.

Barreto et al. ${ }^{35}$ identificaram a família como importante espaço de apoio para o usuário durante o tratamento e para sua reabilitação psicossocial. Paiva et al. ${ }^{17}$ mencionam a ausência de oportunidades de acolhimento à família, o que também pôde-se observar no Caps-AD pesquisado: a família carece de cuidados. 
(2)

As estratégias dos profissionais acerca da família devem levar em conta as diferenças culturais, ou seja, valores e práticas peculiares aos diferentes contextos familiares, de modo que as açốes estejam conectadas à realidade vivenciada, reconhecendo limites e potencialidades ${ }^{29}$. Nesse sentido, é preciso repensar as práticas e os novos lugares sociais para os familiares cuidadores ${ }^{34}$, visto que se está diante de uma família que, além de cuidadora, precisa ser cuidada e fortalecida enquanto sujeito político.

\section{Investimento público}

Relatos acerca de dificuldades relacionadas aos investimentos públicos no serviço também ressaltaram. Para Luíza:

[...] as dificuldades, eu acho que é... dinheiro. [...] Investimento, sabe? Pelo ministério, pelo municipal... eu acho que se tivesse mais investimento, né, ia ser melhor. (Luíza)

Tensóes referentes à alocação de recursos às políticas de saúde não são recentes, sendo debatidas desde pelo menos o contexto precedente à criação do Sistema Único de Saúde (SUS) ${ }^{36,37}$. A Emenda Constitucional n. 95, de 2016, que ficou conhecida como a "PEC do teto de gastos", prevê que o gasto primário do governo federal deve ser limitado por um teto definido pelo montante gasto no ano anterior, reajustado pela inflação acumulada ${ }^{38}$. Essa medida impactou diretamente no investimento em políticas sociais (educação, saúde e segurança), incluindo os recursos disponibilizados ao cuidado oferecido pelas políticas públicas às pessoas que fazem uso de drogas. Ressalta-se que as políticas de cuidado aos usuários de álcool e outras drogas requerem investimentos contínuos e de longo prazo, de modo a garantir a intersetorialidade, a integralidade e a continuidade das açốes ${ }^{4}$. A esse respeito, é importante ressaltar que o orçamento público deve garantir as açóes planejadas pelo Estado e as prioridades das políticas públicas, com o fundo público assegurando recursos suficientes para a execução das políticas sociais ${ }^{37}$. O financiamento e as prioridades de aplicação dos recursos públicos não se manifestam apenas como escolhas econômicas, mas também refletem as opçóes políticas e as forças sociais presentes na sociedade ${ }^{36}$.

Os entrevistados relatam que a exiguidade de recursos cria obstáculos à realização de determinadas atividades de reabilitação psicossocial ou inclusão social. Atividades, por exemplo, que demandam recursos para o deslocamento dos usuários geram despesas adicionais para o serviço. Bruna, a esse respeito, comenta que:

[...] o que impede mais a gente é a questão financeira, né? Porque aí, assim, ora tem transporte, ora não tem transporte, ora a gente tem como pedir que a alimentação vá até eles, mas muitas vezes não tem. (Bruna) 
A falta de investimento adequado nos serviços também é um dos impasses encontrados nas pesquisas de Paiva et al. ${ }^{17}$ e de Barreto et al.${ }^{35}$, sendo discutida também por Dimenstein ${ }^{39}$. Para essa autora, o investimento inadequado e insuficiente do SUS para os serviços substitutivos da rede de atenção psicossocial é um dos fatores que implica na produção de uma atenção pouco diversificada, tornando-a ineficiente na produção de saúde no meio social do indivíduo.

Essa falta de priorização no investimento de recursos materiais e humanos, apontada na pesquisa de Paiva et al. ${ }^{17}$, indica que esse impasse, quando somado às condições de trabalho desfavoráveis à execução de ações de reabilitação/inclusão, incorre em um baixo grau de autonomia dos trabalhadores dos serviços para a construção de novas práticas que atendam efetivamente às demandas que se apresentam e à complexificação da questão social contemporaneamente.

\section{Considerações finais}

Os impasses e desafios encontrados por meio desta investigação apontam para barreiras que têm como consequência a segregação do usuário de drogas de diversos espaços da vida cotidiana, fragilizando e/ou reduzindo o escopo das relações familiares, sociais e de trabalho. Observa-se, ainda, que os impasses abarcam tanto as ações que ocorrem dentro do serviço quanto as atividades extramuros, isto é, que são desenvolvidas em instituiçóes ou espaços fora do Caps-AD.

Os processos de reabilitação psicossocial e de inclusão social esbarram em limitações que necessitam ser consideradas no planejamento e execução das ações, de modo a consolidar as possibilidades de circulação e ocupação dos espaços sociais de maneira efetiva e que contemplem os direitos dos cidadãos. O estigma é apontado como um impasse relevante, em consonância com outras investigaçóes acerca do campo de álcool e outras drogas ${ }^{17,18}$. Constitui-se também uma barreira para as atividades de trabalho e geração de renda, além de afetar diretamente a relação do usuário com a família e com a sociedade no geral. As relaçóes familiares fragilizadas se manifestam também durante o tratamento, dificultando a adesão da família às atividades do serviço e à coparticipação no cuidado.

A investigação realizada permite inferir que a reabilitação psicossocial e a inclusão social são fenômenos complexos e que precisam de uma atenção do poder público, uma vez que, ao serem preteridas no conjunto das ações que visam à atenção integral, criam-se barreiras no cuidado às pessoas com problemas decorrentes do uso de drogas. O investimento público insuficiente, indicado não só por esta pesquisa, mas também por outros estudos ${ }^{17,35,38}$, demonstra ser incoerente com a imprescindibilidade desses processos, considerados como objetivos tanto da $\mathrm{Raps}^{10}$ quanto do Caps-AD ${ }^{8}$. Isso compromete efetivamente a construção de uma política pautada na inclusão social, que reflete criticamente sobre a atual circunstância de marginalização, segregação e exclusão vivida por parte significativa dos usuários de drogas em sua vida cotidiana.

Vale ressaltar ainda que, na iminência de construção desta pesquisa, mudanças substanciais foram realizadas nas políticas de drogas, instituídas pelo já mencionado Decreto n. 9.761, de 11 de abril de 20195, no qual a reinserção social é amplamente mencionada, indicando a relevância do tema proposto nesta pesquisa. Porém, cabe 
ressaltar que as propostas desta nova política, ao enfatizarem a abstinência como fundamento, meio e fim do tratamento e ao negarem a substitutividade como pilar do modelo comunitário de atenção em saúde mental, evidenciam uma concepção de tratamento que não condiz com os princípios da inclusão social cidadã.

A participação, como entrevistados, dos familiares, dos próprios usuários dos serviços e de outros atores sociais da comunidade poderia ampliar a abrangência da análise acerca das dificuldades nos processos de reabilitação psicossocial e inclusão social. Os resultados também ganhariam em extensão com a inclusão de serviços de outras localidades ao invés de um Caps- $\mathrm{AD}$ singular. No entanto, entende-se que a análise apresentada acerca dos impasses e desafios nos processos de reabilitação psicossocial e inclusão social oportuniza repensar o desenvolvimento de açốes locais e as estratégias voltadas para as demandas concretas das pessoas com problemas decorrentes do uso de drogas.

\section{Contribuições dos autores}

Todos os autores participaram ativamente de todas as etapas de elaboração do manuscrito.

\section{Direitos autorais}

Este artigo está licenciado sob a Licença Internacional Creative Commons 4.0, tipo BY (https://creativecommons.org/licenses/by/4.0/deed.pt_BR).

\section{(cc) BY}

\section{Referências}

1. MacRae E. Antropologia: aspectos sociais, culturais e ritualísticos. In: Seibel S, Toscano Jr A, organizadores. Dependência de drogas. São Paulo: Editora Atheneu; 2001. p. 25-34.

2. Duarte MJO. Da lógica manicomial à rede de atenção psicossocial: a questão das drogas no campo da saúde mental e as internações forçadas. In: Fernandez OFRL, Andrade MM, Filho NA, organizadores. Drogas e políticas públicas: educação, saúde coletiva e direitos humanos. Salvador, Brasília: EDUFBA, ABRAMD; 2015. p. 139-53.

3. Brasil. Ministério da Saúde. Portaria no 3.088, de 23 de Dezembro de 2011. Institui a Rede de Atenção Psicossocial para pessoas com sofrimento ou transtorno mental e com necessidades decorrentes do uso de crack, álcool e outras drogas, no âmbito do Sistema Único de Saúde (SUS). Brasília, DF: Ministério da Saúde; 2004.

4. Brasil. Ministério da Saúde. A Política do Ministério da Saúde para atenção integral a usuários de álcool e outras drogas. 2a ed. Brasília, DF: Ministério da Saúde; 2004.

5. Brasil. Presidência da República. Decreto no 9.761, de 11 de Abril de 2019. Aprova a Política Nacional sobre Drogas. Brasília, DF: Secretaria geral, Presidência da República; 2019.

6. Saraceno B. Reabilitação psicossocial: uma estratégia para a passagem do milênio. In: Pitta AMF, organizador. Reabilitação psicossocial no Brasil. São Paulo: Hucitec; 2016. p. 19-26.

7. Kinoshita RT. Contratualidade e reabilitação psicossocial. In: Pitta AMF, organizador. Reabilitação psicossocial no Brasil. São Paulo: Hucitec; 2016. p. 69-74. 
8. Brasil. Ministério da Saúde. Guia estratégico para o cuidado de pessoas com necessidades relacionadas ao consumo de álcool e outras drogas: guia AD. Brasília, DF: Ministério da Saúde; 2015.

9. Brasil. Ministério da Justiça. Lei no 11.343, de 24 de Agosto de 2006. Institui o Sistema Nacional de Políticas Públicas sobre Drogas - Sisnad. Brasília, DF: Ministério da Justiça; 2006.

10. Brasil. Ministério da Saúde. Portaria no 3.088, de 23 de Dezembro de 2011. Institui a Rede de Atenção Psicossocial. Brasília, DF: Ministério da Saúde; 2011.

11. Brasil. Ministério da Saúde. Portaria no 130, de 26 de Janeiro de 2012. Redefine o Centro de Atenção Psicossocial de Álcool e outras Drogas 24 h (CAPS AD III). Brasília, DF: Ministério da Saúde; 2012.

12. Sanches LR, Vecchia MD. Reabilitação psicossocial e reinserção social de usuários de drogas: revisão da literatura. Psicol Soc. 2018; 30:e178335.

13. Sawaia B. Introdução: exclusão ou inclusão perversa? In: Sawaia B, organizador. As artimanhas da exclusão: análise psicossocial e ética da desigualdade social. Petrópolis, RJ: Vozes; 2014. p. 7-13.

14. Minayo MCS. Técnicas de pesquisa. In: Minayo MCS. O desafio do conhecimento: pesquisa qualitativa em saúde. São Paulo: Hucitec; 2010. p. 261-97.

15. Duarte R. Entrevistas em pesquisa qualitativa. Educar (Curitiba). 2004; 1(24):213-25. Doi: http://dx.doi.org/10.1590/0104-4060.357.

16. Bardin L. Análise de conteúdo. Lisboa: Edições 70; 1977.

17. Paiva FS, Ferreira ML, Martins MZF, Barros SLCF, Ronzani TM. A percepção profissional e comunitária sobre a reinserção social de usuários de drogas. Psicol Soc. 2014; 26(3):696-706. Doi: http://dx.doi.org/10.1590/S0102-71822014000300018.

18. Silveira PS, Soares RG, Noto AR, Ronzani TM. Estigma e suas consequências para usuários de drogas. In: Ronzani TM, organizador. Ações integradas sobre drogas: prevenção, abordagens e políticas públicas. Juiz de Fora: Editora UFJF; 2013. p. 251-74.

19. Goffman E. Estigma: notas sobre a manipulação da identidade deteriorada. 4a ed. Rio de Janeiro: LTC; 2012.

20. Parker R. Interseções entre estigma, preconceito e discriminação na saúde pública mundial. In: Monteiro S, Villela W, organizadores. Estigma e saúde. Rio de Janeiro: Fiocruz; 2013. p. 25-46.

21. Corrigan PW. The impact of stigma on severe mental illness. Cogn Behav Pract. 1998; 5(2):201-22. Doi: http://dx.doi.org/10.1016/S1077-7229(98)80006-0.

22. Karam ML. Considerações sobre as políticas criminais, drogas e direitos humanos. In: Vecchia MD, Ronzani TM, Paiva FS, Batista CB, Costa PHA, organizadores. Drogas e direitos humanos: reflexões em tempos de guerra às drogas. Porto Alegre: Rede UNIDA; 2017. p. 211-32.

23. Karam ML. Drogas: dos perigos da proibição à necessidade de legalização. In: Palestra proferida na abertura do Seminário LEAP Brasil - Law Enforcement Against Prohibition, Fórum Permanente de Direitos Humanos da Escola de Magistratura do Estado do Rio de Janeiro (EMERJ) [Internet]; 2013; Rio de Janeiro. Rio de Janeiro: LEAP; 2013 [citado 2 Dez 2017]. Disponível em: https://www.academia.edu/6463992/DROGAS_DOS_PERIGOS_ DA_PROIBI\%C3\%87\%C3\%830_\%C3\%80_NECESSIDADE_DA_ LEGALIZA\%C3\%87\%C3\%83O 
24. Guerra AMC. Oficinas em saúde mental: percurso de uma história, fundamentos de uma prática. In: Costa CM, Figueiredo AC, organizadores. Oficinas terapêuticas em saúde mental: sujeito, produção e cidadania. Rio de Janeiro: Contra Capa; 2008. p. 23-58.

25. Saraceno B. Libertando identidades: da reabilitação psicossocial à cidadania possível. 2a ed. Rio de Janeiro: Te Corá Editora; 2001.

26. Lussi IAO, Matsukura TS, Hahn MS. Reabilitação psicossocial: oficinas de geração de renda no contexto da saúde mental. Mundo Saude. 2011; 35(2):185-92.

27. Ribeiro MBS, Martins STF, Oliveira LR. Familiares de usuários vivenciando a transformação do modelo assistencial psiquiátrico. Estud Psicol. 2009; 14(2):133-40.

28. Reis TL, Dahl CM, Barbosa SM, Teixeira MR, Delgado PGG. Sobrecarga e participação de familiares no cuidado de usuários de Centros de Atenção Psicossocial. Saude Debate. 2016; 40(109):70-85. Doi: http://dx.doi.org/10.1590/01031104201610906.

29. Trad SNS. Princípios e desafios para integração da família nas políticas de drogas. In: Trad LAB, organizador. Família contemporânea e saúde: significados, práticas e políticas públicas. Rio de Janeiro: Fiocruz; 2010. p. 179-97.

30. Zinberg NE. Drug, set, and setting: the basis for controlled intoxicant use. New Haven: Yale University Press; 1984.

31. Silveira PS, Silva EA. Família, sociedade e uso de drogas: prevenção, inclusão social e tratamento familiar. In: Ronzani TM, organizador. Ações integradas sobre drogas: prevenção, abordagens e políticas públicas. Juiz de Fora: Editora UFJF; 2013. p. 209-22.

32. Sanches LR, Santos TGC, Gomes TB, Dalla Vecchia M. Meanings of family support in the treatment of drug dependence. Paidéia. 2018; 28:e2824.

33. Carvalho MCB. Famílias e políticas públicas. In: Acosta AR, Vitale MAF, organizadores. Famílias: redes, laços e políticas públicas. 4a ed. São Paulo: Cortez, Instituto de Estudos Especiais/PUC-SP; 2008. p. 267-74.

34. Rosa LCS. A inclusão da família nos projetos terapêuticos dos serviços de saúde mental. Psicol Rev. 2005; 11(8):205-18.

35. Barreto RO, Lopes FT, Paula APP. A economia solidária na inclusão social de usuários de álcool e outras drogas: reflexóes a partir da análise de experiências em Minas Gerais e São Paulo. Cad Psicol Soc Trab. 2013; 16(1):41-56. Doi: http://dx.doi.org/10.11606/ issn.1981-0490.v16i1p41-56.

36. Salvador E. Fundo público e o financiamento das políticas sociais no Brasil. Serv Soc Rev. 2012; 14(2):4-22. Doi: http://dx.doi.org/10.5433/1679-4842.2012v14n2p4.

37. Maciel SM, Sousa SMPF, Cunha CLF, Mendes AN. O fundo público e o financiamento da política de saúde no Brasil. Soc Debate. 2017; 23(2):97-120.

38. Brasil. Presidência da República. Emenda constitucional no 95, de 15 de Dezembro de 2016. Altera o Ato das Disposiçóes Constitucionais Transitórias, para instituir o Novo Regime Fiscal, e dá outras providências. Brasilia, DF: Casa Civil; 2016.

39. Dimenstein M. O desafio da política de saúde mental: a (re)inserção social dos portadores de transtornos mentais. Mental. 2006; 4(6):69-83. 
Psychosocial rehabilitation and social inclusion, which are related to the possibility of free circulation and participation in society, are challenges faced by professionals of alternative services to psychiatric hospitals. The difficulties faced by professionals in the development and implementation of rehabilitation and inclusion strategies in these services were investigated. Semistructured interviews were conducted with professionals from a Psychosocial Care Center - Alcohol and Drugs (Caps-AD, Centros de Atenção Psicossocial - Alcool e Drogas) and studied using a thematic content analysis. The main deadlocks were: social stigma, shortage of work and income generation activities, family distance during the treatment, and insufficient funding for strategic actions. These are complex phenomena that require government attention, since they build barriers to rehabilitation strategies and social inclusion.

Keywords: Psychosocial rehabilitation. Social inclusion. Drugs. Public policies.

La rehabilitación psicosocial y la inclusión social, cuyas definiciones se relacionan con la posibilidad de circulación en el territorio y participación en la sociedad, constituyen desafíos para los profesionales de servicios substitutivos a los hospitales psiquiátricos. Se investigan las dificultades que los profesionales encuentran en el desarrollo y en la implantación de las estrategias de rehabilitación e inclusión en tales servicios. Se realizaron entrevistas semiestructuradas con profesionales de un Centro de Atención Psicosocial - Alcohol y otras drogas (Caps-AD), analizadas vía análisis de contenido del tipo temático. Los principales callejones sin salida relatados fueron los estigmas sociales atribuidos a los usuarios de drogas, la escasez de actividades de trabajo y generación de renta, el distanciamiento de la familia durante el tratamiento y la financiación insuficiente para acciones estratégicas. Se trata de fenómenos complejos y que precisan atención del poder público por crear barreras a las estrategias de rehabilitación e inclusión social.

Palabras clave: Rehabilitación psicosocial. Inclusión social. Drogas. Políticas públicas. 